\title{
Comparative study of abrasion via microindentation and microscratch tests of reinforced and unreinforced lamellar cast iron
}

\author{
Mohammed MENDAS ${ }^{1, *}$, Stéphane BENAYOUN ${ }^{2}$ \\ ${ }^{1}$ Laboratory of Rheology and Mechanics (LRM), Hassiba Benbouali University of Chlef, Hay Essalem Chlef BP 151 (02000), Algeria \\ ${ }^{2}$ LTDS, UMR CNRS 5513, Ecole Centrale de Lyon, University of Lyon, Ecully Cedex F-69134, France \\ Received: 09 February 2018 / Revised: 11 April 2018 / Accepted: 14 May 2018 \\ (C) The author(s) 2018. This article is published with open access at Springerlink.com
}

\begin{abstract}
This study compares micro-abrasive wear in two kinds of grey cast iron. Classical lamellar cast iron with fully pearlitic matrix (FGL1) and lamellar micro-alloyed cast iron with phosphorus and boron (FGL2) are used. FGL2 has a fully pearlitic matrix reinforced by the hard phosphorus eutectic phase. The microstructures of these two types of iron are mechanically characterized using nanoindentation tests. Vickers microindentation and microscratch tests are also performed on these iron samples. The indent and scratch images obtained via scanning electron microscopy were used to compare the scratch damage to the two kinds of iron. The friction coefficient is discussed in terms of applied load, indenter attack angle, and scratch damage. Nanoindentation tests show an improvement in graphite's mechanical properties and an increase in the matrix hardness of the FGL2, relatively to FGL1. The same damage forms for both microindentation and microscratch testing were observed for the two iron samples. However, cracking of the hard phase is observed in FGL2. The results show that the scratching of the micro-alloyed iron (FGL2) leads to less matrix damage and to an extended microploughing wear mechanism. However, at low normal load, the reinforcement of the matrix can increase the friction coefficient.
\end{abstract}

Keywords: grey cast iron; indentation; microscratch; abrasive; wear

\section{Introduction}

Because of its important qualities, such as good machineability, good castability, high wear resistance, and low production cost, grey cast iron is widely used for many machine elements subjected to friction loading. These elements include cylinder liners [1, 2], crankshafts for heat engines [3], and discs and brake drums for automobiles [4]. Several improvements in tribological performance of cast iron are associated with an optimization of the microstructure [5-7].

Grey iron is distinguished by the presence of graphite in the lamellar form of random orientation and other matrix constituents. The graphite contributes to tribofilm formation and strongly influences the friction coefficient during sliding loading. Indeed, Collini et al. [8] consider graphite to have isotopically perfect elastic behavior and symmetric mechanical properties in tension and compression. However, in the literature, there are many converse effects on its mechanical properties, such as Young's modulus and hardness $[5,9,10]$. Nevertheless, graphite's influence on the matrix deformation and wear mode of cast iron has been the subject of many recent experimental studies $[2,11-13]$.

The judicious choice of additional elements to classical cast iron can significantly improve the matrix hardness and abrasive wear resistance. The addition of boron to the classical grey cast iron at $0.02 \%$ increases the tensile strength and hardness, whereas, beyond this

* Corresponding author: Mohammed MENDAS, E-mail: m_mendas@yahoo.fr,m.mendas@univ-chlef.dz 
value, a decreasing in these properties is observed [14]. Phosphorus is also used in special tribological applications [8] of grey cast iron. Phosphorus leads to the formation of hard and brittle phosphorus eutectic phases, commonly referred to as steadite, which increases the matrix hardness and the wear resistance $[8,15]$. However, steadite is the last element to solidify, which leads to crack nucleation at the matrix-hard phase interface [8] and formation of micro-porosities $[8,14]$. A high level of phosphorus content decreases tensile strength [16], but increases hardness [17].

The existence of these phases (which are harder than the matrix) and the presence of graphite (as a soft phase), in addition to a lack of information about the nature of the interface, make it difficult to understand grey cast iron behavior in abrasive wear. However, interactions between the matrix and these phases during sliding require further investigation. Recently, several experimental techniques have been used to examine the macroscopic abrasion of grey cast iron $[18,19]$. Other investigations of their microscopic abrasion wear via microindentation and microscratching have been performed [11-13], in addition to nanoscratch tests [20]. In most of these experimental studies, the tribological behavior of the cast iron is discussed based on the test conditions and the addition of different chemical elements on the iron's microstructure. Ghasemi et al. [13] have studied the microstructural response of lamellar cast iron via microscratch tests under constant and progressive loading. They found that when scratch load increased, the friction coefficient increased, but decreased based on the wear mode mechanism.

This study attempts to compare the abrasive wear of two kinds of lamellar grey cast iron using microindentation and microscratch tests. The first sample has a pearlitic matrix and the second one has a pearlitic matrix reinforced by a hard phase. Thus, two types of grey cast iron were used: classical lamellar (without a hard phase) and cast iron alloyed with phosphorus and boron. First, all microstructural constituents of the two types of cast iron were mechanically characterized using nanoindentation. Second, microindentation Vickers and microscratch tests were performed under several loading conditions. The behavior of the constituents of iron and the elementary wear damage after microindentation and microscratch tests are analyzed using scanning electron microscopy (SEM). An evaluation of the evolution of the apparent friction coefficient as a function of the applied normal load and the indenter geometry was performed.

\section{Experimental details}

\subsection{Materials}

Two types of grey cast iron were used: classical grey cast iron (FGL1) and micro-alloyed grey iron with phosphorus and boron (FGL2). Their chemical compositions are given in Table 1. The nickel and copper quantities in these iron samples are different; these two elements affect the graphite morphology and refine the pearlite [18]. Cu leads to a purely pearlitic matrix, increases the hardness, and decreases the friction coefficient [21].

The samples were obtained from the cylinder liners of a diesel engine of a heavy vehicle. The microstructure of this grey cast iron (Fig. 1), after etching with Nital reagent $(4 \%)$, was examined via SEM. FGL1 iron has a pearlitic matrix and lamellar graphite (Fig. 1(a)) and FGL2 iron (Fig. 1(b)) has a pearlitic matrix with hard phases of phosphorus eutectic and carbides, in addition to, lamellar graphite. Energy dispersive spectrometry (SEM/EDX) analyzes and mapping (Fig. 1(c)) reveal that the hard phase contains $\mathrm{Fe}, \mathrm{P}$, and $\mathrm{Mn}$.

The straight lines (Fig. 1) correspond to the different zones from which the pearlite interlamellar spacing was determined. The pearlite phase of FGL1 iron is coarser than that of FGL2 iron and the hard phases are randomly distributed. In both kinds of iron, graphite lamellae of A-type morphology are uniformly

Table 1 Chemical composition (\% in weight) of the studied cast irons.

\begin{tabular}{cccccccccccc}
\hline Cast iron & $\mathrm{C}$ & $\mathrm{Si}$ & $\mathrm{S}$ & $\mathrm{P}$ & $\mathrm{Mn}$ & $\mathrm{Ni}$ & $\mathrm{Cr}$ & $\mathrm{Cu}$ & $\mathrm{Mo}$ & $\mathrm{B}$ \\
\hline FGL1 & 3.24 & 2.06 & 0.036 & 0.087 & 0.904 & 0.46 & 0.245 & 0.221 & 0.247 \\
FGL2 & 3.15 & 2.54 & 0.042 & 0.238 & 0.782 & 0.108 & 0.321 & 0.401 & 0.302 & 0.065 \\
\hline
\end{tabular}




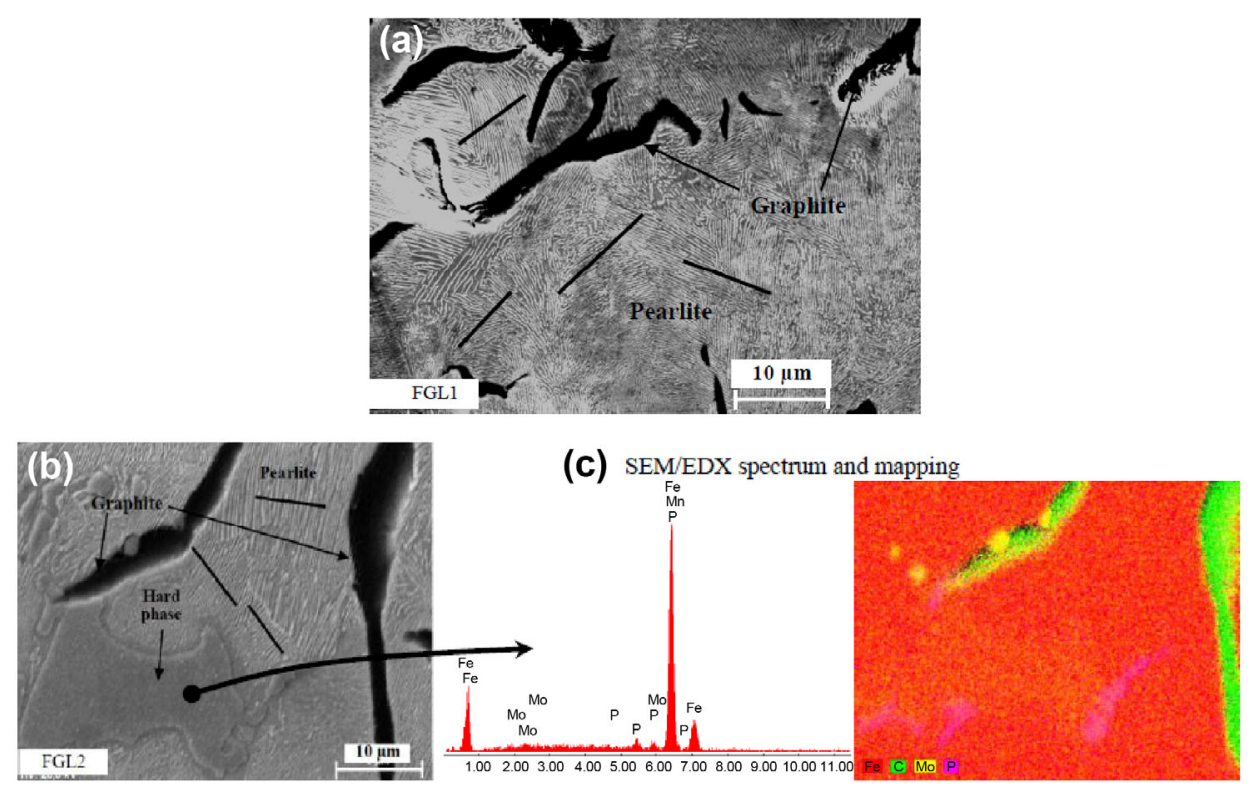

Fig. 1 Microstructures of the studied grey cast irons: (a) classical lamellar iron FGL1, (b) microalloyed lamellar iron FGL2, and (c) SEM/EDX spectrum and mapping at the hard phase (eutectic-phosphorous).

distributed and randomly oriented. The graphite lamellae have varying widths and lengths (Figs. 1(a) and 1(b)). The dimensions of graphite lamellae range from 25 to $100 \mu \mathrm{m}$ in length and from 5 to $10 \mu \mathrm{m}$ in width. The matrix of FGL1 iron is coarser than that of FGL2.

\subsection{Experimental procedure}

Samples preparation, for both metallographic observation and (nano, micro)-indentation and microscratch tests, is of major importance. The retention of graphite in cavities and polishing without surface alterations are important goals. However, grinding with $\mathrm{SiC}$ papers and finishing using a diamond solution is a suitable preparation method for cast iron samples [22]. Therefore, the samples were gradually polished using various abrasive papers ( $\mathrm{SiC}$ ), grades 2000 to 4000. Finishing was carried out with a $3 \mu \mathrm{m}$, and then a $1 \mu \mathrm{m}$, diamond solution.

In addition to microhardness testing, nanoindentation tests were performed on the different iron samples. The nanoindentation tests were conducted with a maximum load of $450 \mathrm{mN}$ on both the matrix and the hard phase. A load of $250 \mathrm{mN}$ was used for the graphite phase. These tests were carried out on a Nanoindenter $\mathrm{XP} \circledast$ installation with a Berkovich-type diamond indenter. The Young's modulus and nano- hardness were determined using the method of continuous stiffness measurement as a function of tip penetration. This method uses the measurement of the second harmonic of the displacement signal of the indenter to determine the mechanical properties [23]. All realized nanoindentations are performed on the middle of each tested phase. The microindentation tests were performed under a constant load varying from 10 to $1,000 \mathrm{~g}$. The dry microscratch tests, at a constant scratching speed of $0.25 \mathrm{~mm} / \mathrm{min}$, were carried out with conical diamond indenters, which had the same tip radius of $5 \mu \mathrm{m}$ and different apex angles, $2 \theta$, of $90^{\circ}, 120^{\circ}$, and $160^{\circ}$. Three constant normal loads were applied during the scratch tests: 1,3 , and $5 \mathrm{~N}$.

\section{Results and discussion}

\subsection{Indentation testing}

\subsubsection{Nanoindentation}

The curves in Fig. 2 show the nanohardness of pearlitic matrix of FGL1 and FGL2 iron and the phosphorus eutectic of FGL2 iron. A low dispersion of matrix hardness of FGL1 iron is obtained; an average hardness of about 2.5 GPa is obtained (Fig. 2(a)). Conversely, in the case of FGL2 iron, the matrix nanohardness is more dispersed than that of the matrix of FGL1 iron 

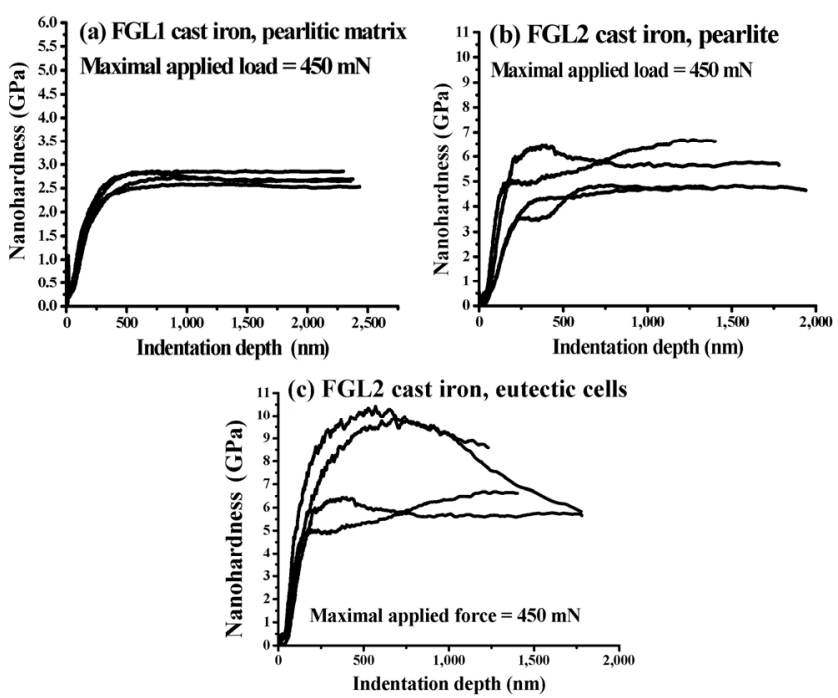

Fig. 2 Pearlite and eutectic cells nanohardnesses of the two studied irons.

(Fig. 2(b)). This result is attributed to the finer pearlitic matrix of FGL2 and to the presence of the harder phosphorus eutectic.

Nanohardness values varying from 4 to $6 \mathrm{GPa}$ are obtained on the matrix of the micro-alloyed iron (FGL2). The nanohardness of the phosphorus eutectic in FGL2 iron (Fig. 2(c)) varies from 6 to $10 \mathrm{GPa}$. The different components of the phosphorus eutectic $\left(\mathrm{Fe}_{\alpha^{\prime}}\right.$ $\mathrm{Fe}_{3} \mathrm{C}$, and $\left.\mathrm{Fe}_{3} \mathrm{P}\right)$ [8] may be the cause of this variation in nanohardness (Fig. 2(c)). Furthermore, SEM examination (Fig. 1(b)) shows the interface of the small thickness between the hard phase and the matrix. The possible presence of shrinkage micro-porosity $[8,14]$ at this interface can also cause the hardness difference.

Figures 3 and 4 show the nanohardness and the Young's modulus of the graphite phase, respectively. The increasing hardness and Young's modulus of graphite with increased depth is due to both its small size and the influence of the matrix with better mechanical properties than the graphite phase. At this scale, a slight increasing of the graphite hardness and Young's modulus of FGL2, relative to those of FGL1, is observed. The nanohardness is 0.08 and $0.15 \mathrm{GPa}$ and the Young's moduli are 12 and $18 \mathrm{GPa}$ for FGL2 and FGL1, respectively.

Comparing the two grey iron samples (Figs. 2-4), we see that the addition of phosphorus and boron slightly increases the nanohardness and the Young's modulus of graphite. Furthermore, these elements
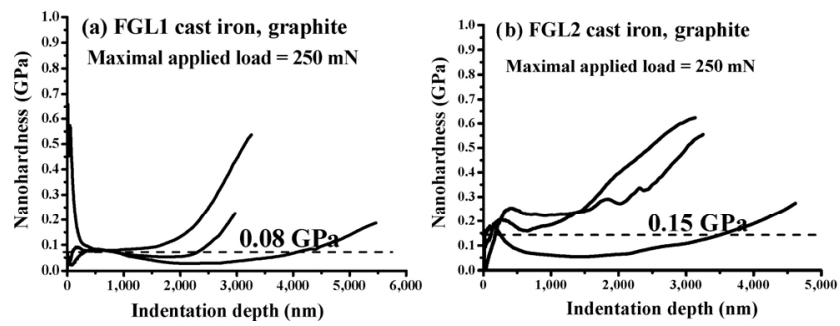

Fig. 3 Nanohardness of graphite phase in FGL1 and FGL2 cast irons.
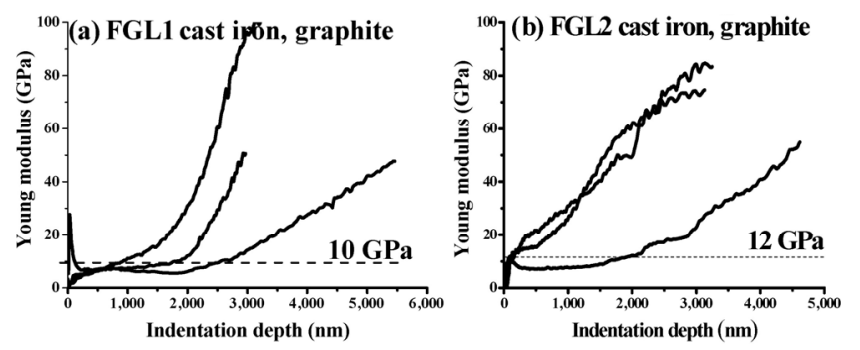

Fig. 4 Young's modulus of graphite phase in FGL1 and FGL2 cast irons.

improve the matrix hardness and reinforce it based on hard phosphorus eutectics.

\subsubsection{Microindentation}

Figure 5 shows the SEM images of indents in the two iron samples. These images show that when the graphite is under the indenter (and because of its low hardness), it decreases the pressure applied by the indenter, and consequently, reduces the matrix deformation. Figure 5 shows that the graphite parallel to the indentation edge is extruded more than the perpendicular graphite (Figs.5(a) and 5(b)). The graphite located within the indent is divided into two sides based on the pearlitic matrix (Fig. 5(e)). In addition, the image in Fig. 5(d) shows that the hard phosphorus eutectic is plastically deformed under the indenter (within the indent); however, cracking of this phase outside the indent (top and left) is observed. In the case of FGL2 iron, a crack is created in the phosphorus eutectic located outside the indentation zone (Fig. 5(d)). We believe that the graphite-matrix interface always retains graphite, which leads us to the conclusion that the matrix-graphite interface is different (i.e., more resistant than the graphite itself). This assumption can explain the rapid increase in nanohardness of the graphite phase (Fig. 3).

SEM examinations of the Vickers indents (Figs. 5(c) 
and $5(f))$ indicate that the graphite extrusion beneath the indenter is attributed to the elastic recovery of the pearlitic matrix. In addition, the graphite at the side of the indent is extruded either via the indentation pressure or via the interconnection with material beneath the indenter. The indent for a load of $500 \mathrm{~g}$ simultaneously performed on matrix and graphite (Figs. 5(c) and 5(f)) is not square. Therefore, we conclude that the plastic deformations of the matrix under the indenter are altered by the graphite lamellae and that the elastic recovery of the matrix and its plastic deformation are not regular in the deformed volume beneath the indenter.

\subsection{Microscratch testing}

\subsubsection{Damage and wear modes}

Figure 6 highlights the global behavior of the two studied iron samples during scratch tests. For a given attack angle, the damage caused by scratching of the two iron samples becomes significant when the load increases. When the attack angle is high, the damage is worse in FGL1 (Fig. 6(c)) than in FGL2 (Fig. 6(f)). The scratch behavior of the studied cast iron samples depends on the indenter geometry, especially its attack angle, and therefore, the scratching depth [11]. Thus, for low normal loads and low indenter attack angles, the pearlitic matrix deforms with the same modes as observed in homogeneous materials.

In the first approximation (as the tip radius is small compared to the groove width), the generated mean deformation is relatively constant and depends only on the attack angle $(\varepsilon \approx 0.2 \tan \beta$ with $\beta$ is the indenter attack angle) [24]. Therefore, the increase in the normal force primarily induces an increase in the volume of displaced material (with a greater possibility of

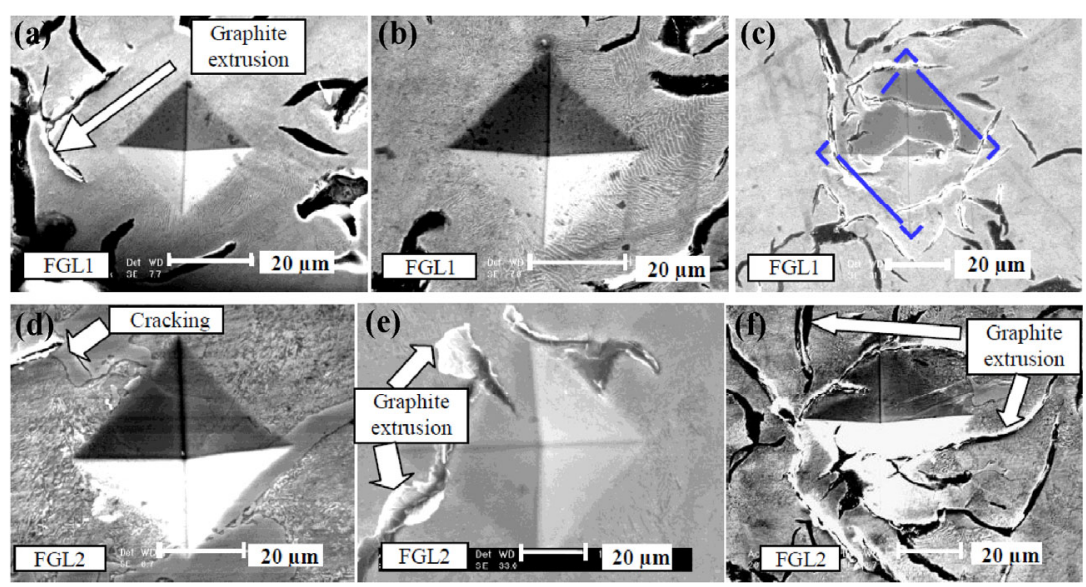

Fig. 5 Vickers indents SEM images of matrix cast iron, load test, from left to right: 100, 200 and 500 g, respectively.
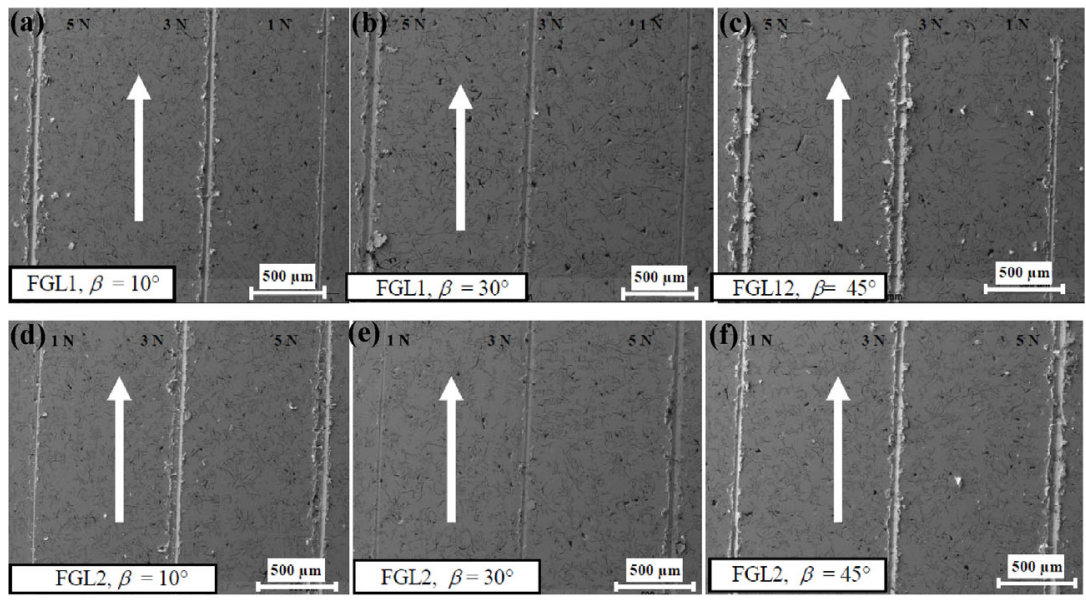

Fig. 6 SEM images of scratch damage on studied irons vs. normal load, $F_{\mathrm{n}}(1,3$, and $5 \mathrm{~N})$ and indenter attack angle, $\beta$ (the arrows show the scratching direction). 
interaction with the graphite lamellae). For both iron samples, when the applied normal force and the attack angle are low, a microploughing wear mode dominates scratching, with no lateral material displacement (Figs. 6(a), 6(d), 7(a), and 8(a)). When these two test parameters become high, a mixture of microploughing and microcutting characterizes the wear mechanism (Figs. 6(c) and 6(f)). The microcutting wear mode occurs with lateral and frontal material displacement (Figs. 6(c), 6(f), and 7(b)). In general, the scratching of FGL1 (Fig. 6(c)) leads to more material displacement than that of FGL2 (Fig. 6(f)).

The SEM images in Figs. 7 and 8 show the scratching behavior of the matrix of the two iron samples for a low attack angle $\left(10^{\circ}\right)$ and three normal loads: $1 \mathrm{~N}, 3 \mathrm{~N}$, and $5 \mathrm{~N}$. Using this attack angle, the microploughing and microcutting mechanisms are more easily distinguished than for the other attack angles $\left(30^{\circ}\right.$ and $45^{\circ}$ ). These two scratch parameters lead to less damage and microploughing dominates the wear mechanism. However, ploughing of FGL1 results in more material displacement than FGL2 (Fig. 7(b)); however, for FGL2, a crack is created at the hard phase, as shown in the circles in Fig. 8(b), as was also observed by Pöhl et al. [25]. This crack is created in the phosphorus eutectic, rather than at its interface with the matrix. However, under the indenter, these hard phases are plastically deformed (in addition to the matrix), with no cracking (Fig. 8(a)).

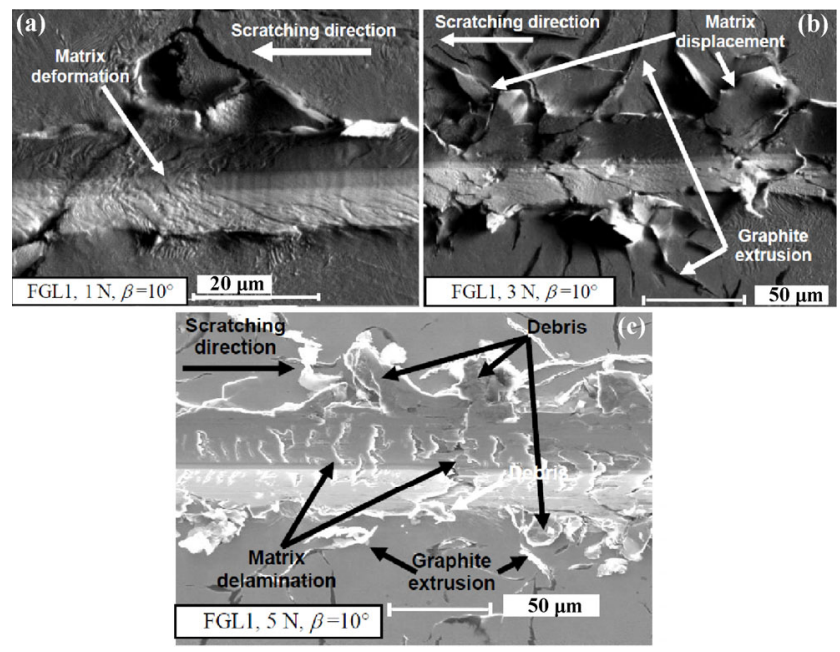

Fig. 7 Pearlite matrix deformation and formation of debris, FGL1 iron, indenter apex angle $2 \theta=160^{\circ}$ (attack angle, $\beta=10^{\circ}$ ), $F_{\mathrm{n}}=1,3$, and $5 \mathrm{~N}$.

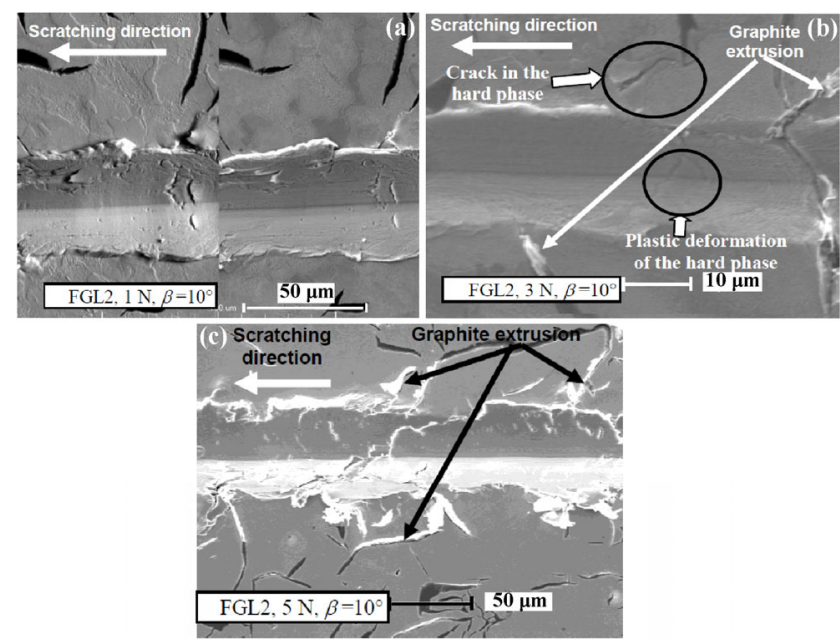

Fig. 8 Pearlitic matrix deformation and cracking of hard phosphorous eutectic, FGL2 iron, $2 \theta=160^{\circ}$ (attack angle, $\beta=10^{\circ}$ ), $F_{\mathrm{n}}=1,3$, and $5 \mathrm{~N}$.

The same behavior of this hard phase is observed in the case of microindentation (Fig. 5(d)). Zum Gahr [26] shows that the cracking of hard phases depends on the size and hardness of the abrasive particles. Therefore, in the case of scratching of the micro-alloyed iron by a hard diamond indenter, the cracking of the eutectic phase is attributed to the depth of scratching, which determines the particle size relative to the size of the hard phase. There are also differences between the FGL1 and FGL2 iron samples during scratching (Figs. 6-8). These differences are attributed both to the coarseness of the pearlitic matrix and to the existence of hard phosphorus eutectic. The SEM image in Fig. 7(b) shows that the extrusion of graphite occurs at the interconnected lamellae, some of which are placed under the indenter. The material displacement at the side of the scratches occurs primarily at a small piece of pearlite material surrounded by graphite lamellae. However, the extrusion of the graphite depends not only on its dimension (specifically, its width) and its position with respect to the scratching zone [11, 12], but also on its interconnectivity.

Scratching induces ductile deformation of the pearlitic matrix formed by alternating lamellae of hard cementite and soft ferrite (Figs. 7(a) and 8(a)), in addition to the deformation of the graphite lamellae and of the hard phase (Fig. 8(b)). In the case of FGL1 iron, the deformation of the pearlitic matrix increases with increasing applied normal load (Fig. 7(b)). These 
deformations are amplified because of the existence of graphite lamellae perpendicular to the direction of sliding. As observed via SEM analysis, the higher applied load and attack angle, the higher the deformed volume around the indenter, and thus, the larger the amount of graphite in its composition. Consequently, the displacement and deformation of the matrix become more significant.

Both cast iron samples exhibit similar behaviors, in terms of graphite extrusion phenomena and the matrix displacements, in both microindentation and microscratch tests. The hard phase of FGL2 iron is cracked by both indentation and scratch tests. Under the same normal load and indenter attack angle, the FGL2 exhibits less matrix delamination and material displacement than the FGL1 (Figs.7(c) and 8(c)). Therefore, we believe that the addition of phosphorus and boron reinforces the iron matrix via the hard phase, improving the hardness of the matrix. Consequently, the reinforcement of the matrix reduces matrix damage and enhances the ploughing wear mechanism.

\subsubsection{Friction coefficient}

Figures 9 and 10 show the evolution of the apparent friction coefficient (ratio of tangential force, $F_{\mathrm{t}}$, to normal force, $\left.F_{\mathrm{n}}\right)$ for a short sliding distance $(500 \mu \mathrm{m})$ versus the attack angle for two normal loads of $1 \mathrm{~N}$ and $5 \mathrm{~N}$.

While the applied load is low $\left(F_{\mathrm{n}}=1 \mathrm{~N}\right)$, the friction coefficient fluctuates for all of the tested attack angles for both kinds of cast iron (Fig. 9). Under this scratching condition, the friction coefficient increases with increasing attack angle. When the ploughing mode dominates the scratching (low normal load and low attack angle), FGL2 is scratched with a friction coefficient greater than that of FGL1 (Fig. 9(a)). The findings shown on Figs. 9(a) and 9(b) lead to the conclusion that the transition from the ploughing mode to the cutting mode occurs first for FGL1, rather than for FGL2. However, while using an indenter with a high attack angle of $45^{\circ}$ (Fig. 9(c)), both cast iron samples are scratched via the cutting wear mode, and consequently, the same friction coefficient is obtained. When the applied normal force is increased to $5 \mathrm{~N}$ (Fig. 10), the friction coefficient of FGL2 is higher than of FGL1. As compared to scratching with a low applied force of $1 \mathrm{~N}$, the friction coefficient slightly fluctuates. Applying a normal load of $5 \mathrm{~N}$, the microcutting wear mechanism is obtained for both cast iron samples with an attack angle of $30^{\circ}$ (Fig. 10(b)).

At high indenter attack angles, the amplitude and the period of the friction coefficient fluctuation are
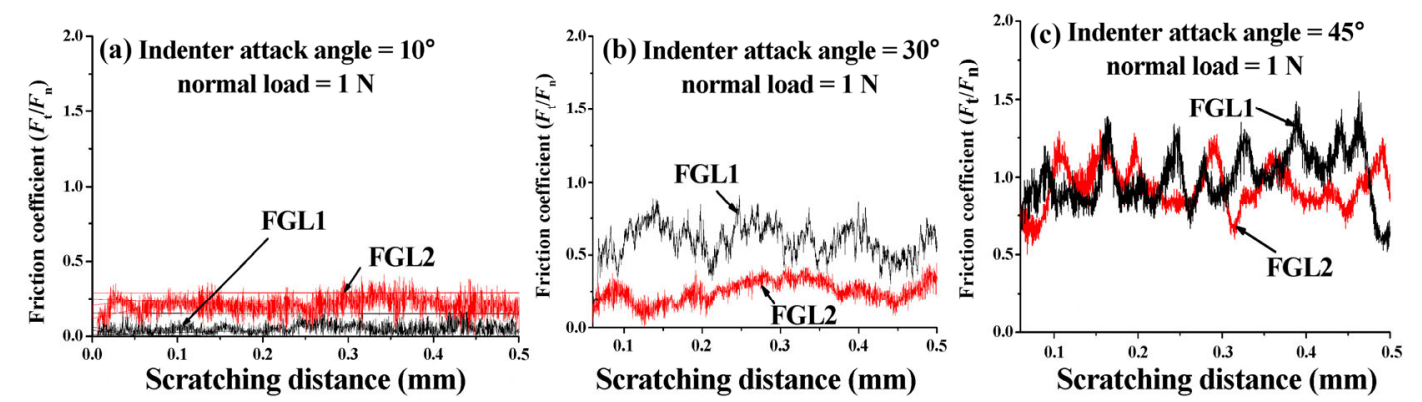

Fig. 9 Friction coefficient vs. scratching distance and indenter attack angle (normal load $=1 \mathrm{~N}$ ).
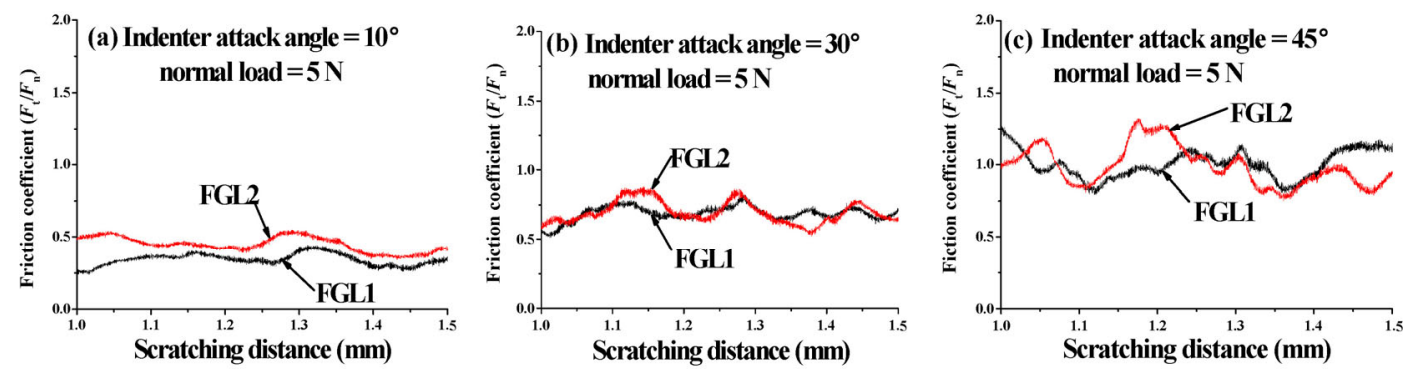

Fig. 10 Friction coefficient vs. scratching distance and indenter attack angle (normal load $=5 \mathrm{~N}$ ). 
nearly the same for both cast iron samples (Figs. 9(c) and 10(c)). Thereafter, the friction coefficient becomes invariable at a normal load of $5 \mathrm{~N}$ and indenter attack angles of $30^{\circ}$ and $45^{\circ}$ (Figs. 9(b), 9(c), 10(b), and 10(c)). We assume that the wavering of the friction coefficient and the stick-slip phenomenon are not only due to the crossed graphite area $[11,20]$, but also to the displacement and smearing of wear debris by the indenter, in addition to the matrix delamination. We assume that this phenomenon is enhanced for high normal loads, particularly, for high indenter attack angles (Figs. 9(c) and 10(c)).

Given the qualitative and quantitative results (Figs. 6-10), it is clear that the reinforcement of the iron matrix with phosphorus eutectic reduces the matrix damage and the friction coefficient. In addition, the ploughing wear mechanism is more prominent for FGL2 than for FGL1. The hard phosphorus eutectic can reverse the changes in the friction coefficient and can enhance the ploughing wear mechanism.

\section{Conclusions}

This paper presents a comparison of measured mechanical properties of different microstructural constituents for the microindentation and microscratching behavior of two kinds of grey cast iron. The main conclusions are the following.

The alloying of phosphorus and boron in the lamellar cast iron increases both the nanohardness and Young's modulus of graphite and the matrix hardness. Regarding microindentation, similar behavior of graphite is obtained for the two cast iron samples. Both microindentation and microscratch tests of the micro-alloyed iron lead to cracking of the hard phosphorus eutectic.

The scratch behavior of the two iron samples showed that the indenter attack angle and the applied normal load combined with the graphite lamellae and hard phase were the most significant contributions to the wear mechanisms and the friction coefficient evolution. The intermediate abrasive wear mode is difficult to identify. However, scratching of the micro-alloyed grey iron (FGL2) is dominated by a microploughing wear mechanism, relative to classical grey iron (FGL1).

Many phenomena are observed during cast iron scratching: graphite extrusion, debris smearing, matrix delamination, and hard phase cracking. Generally, the reinforcement of the grey iron's matrix by the hard phosphorus eutectic phase leads to less matrix damage, less material displacement, and a lower friction coefficient.

Open Access: The articles published in this journal are distributed under the terms of the Creative Commons Attribution 4.0 International License (http:// creativecommons.org/licenses/by/4.0/), which permits unrestricted use, distribution, and reproduction in any medium, provided you give appropriate credit to the original author(s) and the source, provide a link to the Creative Commons license, and indicate if changes were made.

\section{References}

[1] Álvarez L, Luis C J, Puertas I. Analysis of the influence of chemical composition on the mechanical and metallurgical properties of engine cylinder blocks in grey cast iron. J Mater Process Technol 153-154: 1039-1044 (2004)

[2] do Vale J L, Cortz M, Bertolini V M S, da Silva C H, Pintaude G. Comparison of scratch resistance of lamellar and compacted graphite irons used in cylinder liners. J Braz Soc Mech Sci Eng 39(10): 3981-3988 (2016)

[3] Ghaderi A R, Nili Ahmadabadi M, Ghasemi H M. Effect of graphite morphologies on the tribological behavior of austempered cast iron. Wear 255(1-6): 410-416 (2003)

[4] Blau P J, Meyer III H M. Characteristics of wear particles produced during friction tests of conventional and unconventional disc brake materials. Wear 255(7-12): 1261-1269 (2003)

[5] He Z R, Lin G X, Ji S. A new understanding on the relation among microstructure micro interfacial mechanical behaviours and macro mechanical properties in cast iron. Mater Sci Eng: A 234-236: 161-164 (1997)

[6] Dai W S, Chen L H, Lui T S. A study on $\mathrm{SiO}_{2}$ particle erosion of flake graphite and spheroidal graphite cast irons. Wear 239(1): 143-152 (2000)

[7] Prasad B K. Sliding wear response of cast iron as influenced by microstructural features and test condition. Mater Sci Eng: A 456(1-2): 373-385 (2007)

[8] Collini L, Nicoletto G, Konečná R. Microstructure and mechanical properties of pearlitic gray cast iron. Mater Sci Eng: A 488(1-2): 529-539 (2008)

[9] Suha A Y, Patel J J, Polycarpou A A, Conry T F. Scuffing of cast iron and Al390-T6 materials used in compressor applications. Wear 260(7-8): 735-744 (2006) 
[10] Andriollo T, Thorborg J, Hattel J. Modeling the elastic behavior of ductile cast iron including anisotropy in the graphite nodules. Int J Solids Struct 100-101: 523-535 (2016)

[11] Mendas M, Benayoun S. Investigating the effects of microstructure on the wear mechanisms in lamellar cast irons via microscratch tests. Tribol Int 67: 124-131 (2013)

[12] Ghasemi R, Elmquist L. A study on graphite extrusion phenomenon under the sliding wear response of cast iron using microindentation and microscratch techniques. Wear 320: 120-126 (2014)

[13] Ghasemi R, Elmquist L, Ghassemali E, Salomonsson K, Jarfors A E W. Abrasion resistance of lamellar graphite iron: Interaction between microstructure and abrasive particles. Tribol Int 120: 465-475 (2018)

[14] Ankamma K. Effect of trace elements (Boron and Lead) on the properties of gray cast iron. $J$ Inst Eng (India): Ser D 95(1): 19-26 (2014)

[15] Keller J, Fridrici V, Kapsa P, Vidaller S, Huard J F. Influence of chemical composition and microstructure of gray cast iron on wear of heavy duty diesel engines cylinder liners. Wear 263(7-12): 1158-1164 (2007)

[16] Abbasi H R, Bazdar M, Halvaee A. Effect of phosphorus as an alloying element on microstructure and mechanical properties of pearlitic gray cast iron. Mater Sci Eng: A 444(1-2): 314-317 (2006)

[17] Tomlinson W J, Dennison G. Effect of phosphide and matrix microstructures on the dry sliding wear of grey cast iron. Tribol Int 22(4): 259-264 (1989)

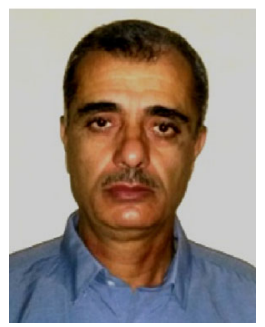

Mohammed MENDAS. He received his $\mathrm{PhD}$ degrees at the University of Science and Technology of Oran, Algeria, in 2007. Since 2008, he is an assistant professor at Mechanical Department and head of materials

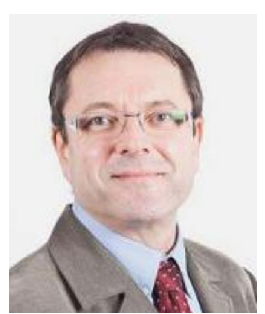

Stéphane BENAYOUN. He received his $\mathrm{PhD}$ degree and accreditation to supervise research (HDR) in material physics from the University of Poitiers, France. Since 2005, he is professor at the Department of Materials Science and Surface
[18] Vadiraj A, Balachandran G, Kamaraj M, Gopalakrishna B, Rao D V. Wear behavior of alloyed hypereutectic gray cast iron. Tribol Int 43(3): 647-653 (2010)

[19] Vélez J M, Tanaka D K, Sinatora A, Tschiptschin A P. Evaluation of abrasive wear of ductile cast iron in a single pass pendulum device. Wear 251(1-12): 1315-1319 (2001)

[20] Nakamura R, Iwabuchi A. Role of graphite in cast iron on tribological behavior in nano-scratch test. $J$ Adv Mech Des, Syst, Manuf 6(7): 1046-1056 (2012)

[21] Razumakov A A, Stepanova N V, Bataev I A, Lenivtseva O G, Riapolova I I, Emurlaev K I. The structure and properties of cast iron alloyed with copper. IOP Conf Ser: Mater Sci Eng 124(1): 012136 (2016)

[22] Radzikowska J M. Effect of specimen preparation on evaluation of cast iron microstructures. Mater Charact 54(4-5): 287-304 (2005)

[23] Guillonneau G, Kermouche G, Bec S, Loubet J L. Extraction of mechanical properties with second harmonic detection for dynamic nanoindentation testing. Exp Mech 52(7): 933-944 (2012)

[24] Tabor D. The Hardness of Metals. Oxford (UK): Clarendon Press, 1951.

[25] Pöhl F, Mohr A, Theisen W. Effect of matrix and hard phase properties on the scratch and compound behavior of wear resistant metallic materials containing coarse hard phases. Wear 376-377: 947-957 (2017)

[26] Zum Gahr K H. Wear by hard Particles. Tribol Int 31(10): 587-596 (1998)

and surfaces mechanics team at the laboratory of rheology and mechanics (LRM) at University of Chlef, Algeria. Research fields cover the tribology, coatings, abrasion (indentation, scratching), and heterogeneous materials (cast irons, composite).

Engineering and the Tribology and System Dynamics Laboratory (LTDS) at Central School of Lyon, France. His research fields are the mechanical behaviour of deposited film, adhesion, tribology, elementary mechanisms of abrasion (indentation, scratching), wetting and laser structuration. 